УДК 294(540)(045)

\title{
Б.P. Ерохин
}

\section{БУДДИЙСКОЕ НАСЛЕДИЕ КАЛИНГИ (СОВРЕМЕННЫЙ ШТАТ ОДИША, ИНДИЯ)}

Статья посвящена рассмотрению взаимодействия автохтонных, буддийских и индуистских традиций в исторической перспективе на материале публикаций современной исторической школы штата, описывающих археологические и эпиграфические памятники Одиши. В отличие от доминирующего в индийской историографии «брахманического» подхода, принижающего влияние буддизма на индийском субконтиненте, в исследованиях местной школы в большей степени отражён этот формирующий фактор в отдалённом от эпицентров национальных событий регионе, где буддизм был абсорбирован и вытеснен индуизмом позднее. Во вступлении описывается ранний период связей Калинги с буддизмом; основная часть статьи посвящена обзору свидетельств смешения и постепенного адаптирования буддийских образов и символов в индуизме, выдающихся фигур буддизма, чья жизнь связана с Одишей, и основных археологических памятников штата. Заключение содержит обобщение исторического процесса ассимиляции буддийских идей и практик на индийском субконтиненте, завершившегося в XIII-XIV вв. вытеснением буддизма на большей части территории региона.

Ключевые слова: ваджраяна, тантризм, индуизм, межрелигиозное взаимодействие, национальная историография.

DOI: $10.35634 / 2412-9534-2020-30-1-119-125$

Одиша (Орисса) - страна между хребтом Виндхья и побережьем Бенгальского залива, в древности известная также как Калинга и Одра. И в наши дни она сохраняет отчётливое своеобразие, с просвечивающими сквозь друг друга религиозно-социальными слоями: верованиями и обычаями первобытных племён джунглей, совместным сильным влиянием джайнизма и буддизма, чьи учения были широко распространены в регионе на протяжении более тысячи лет, и, наконец, доминированием по сегодняшний день индуизма, вобравшего в себя многие черты предыдущих традиций. История штата - показательный пример межрелигиозного взаимодействия, в наши дни интересующего значительную российскую аудиторию последователей буддизма ваджраяны («Алмазной колесницы» быстрого достижения состояния будды), в то время как в современном массовом сознании понятие тантры чаще всего соотносится с шиваизмом. Интерес к данной тематике появился в рамках проводимого автором исследования и перевода раннего трактата «Драгоценные украшения Освобождения» Гампопы Сёнама Ринчена (sGam po pa bsod nams rin chen, 1079-1153), оказавшего существенное влияние на процесс адаптации в Тибете буддизма.

Известно, что купцы Тапусса и Бхаллика, ставшие первыми учениками Будды на седьмой неделе после достижения им Пробуждения, встретились с ним, начав своё путешествие в Калинге [7, p. 80; 3, p. 5]. В последней главе Буддхавамсы из Кхудакка-никаи описывается перемещение реликвии Будды, его зуба, в столицу Калинги; позднее эта реликвия была перевезена на Шри Ланку, где почитается до настоящего времени в Канди. В буддийских сутрах нет упоминаний о пребывании Шакьямуни в Калинге, но в разделе джатак (историй рождений Будды) обитатели этой страны упоминаются не раз. Калинга-бодхи-джатака, в частности, содержит классическое описание местности вокруг дерева бодхи, где все будды достигают просветления (совр. Бодхгая, штат Бихар) [9, I, p. 583-585].

Первые эпиграфические свидетельства о буддизме в Одише связаны с эпохой Ашоки. На восьмом году своего правления, в 262 г. до н. э., царь, стремившийся объединить всю Индию, устроил грандиозное сражение, ставшее поворотным в его духовном и политическом развитии. Впоследствии первый всеиндийский император обращал особое внимание на благополучие и процветание Калинги. В двух крупнейших центрах страны, Дхаули и Джаугархе, дистрикт Ганджам, он приказал выбить на скалах и колоннах свои эдикты [3, p. 8; 15, p. 23]. Только в Дхаули, в 6 км от Бхубанешвара, сохранилось 16 надписей, венчаемых полутораметровой высеченной из скалы скульптурой слона. Некоторые из пещер несут свидетельства того, что в них обитали буддийские отшельники вплоть до XV в. Буддийскую значимость этого места подчёркивает современная величественная Ступа мира, построенная японским обществом [15, p. 49].

В 10 км от эдиктов Ашоки находятся также буддо-джайно-индуистские комплексы Удаягири (18 пещер) и Кхандагири (15 пещер) со скульптурами, надписями дарителей, фундаментами храмов и ступ, датируемые веками рубежа нашей эры. В одной пещере Удаягири также была найдена надпись 
I-II вв. н. э., в которой впервые упомянуты сиддхи - те, кто достиг осуществления сверхъестественных способностей. Правда, этот термин скорее относился к аскетам-джайнам [4, p. 174-175].

Первые века после Ашоки самой влиятельной школой тхеравады (первого цикла учений Будды) в Одише были сарвастивадины, но ко времени визита Сюань Цзана школа самматия, во многом благодаря деятельности Праджнягупты (конец VI в.), поддерживаемого могущественным Харшавардханой, стала самой популярной [20]. Велика вероятность первоначального распространения учений махаяны (цикл учений, получивший распространение с I в. до н. э.) именно в регионе Калинги, поскольку ранняя, начала нашей эры, сутра «Белого лотоса подлинной Дхармы» часто упоминает область Вираджу (современный Джаджпур) [15, p. 26]. Эти учения были хорошо известны в Одише; в частности, в VIII в. царь Удра подарил китайскому императору собственноручно переписанную им расширенную версию Аватамсака-сутры, которую с этой версии уже в третий раз перевели на китайский $[23$, p. 1$]$.

Наряду с Бенгалией и пригималайскими регионами, Одиша должна считаться сферой зарождения и расцвета тантрических течений. По одной из версий, Будда здесь изложил учения Калачакры Сучандре, первому дхарма-царю Шамбхалы [2, р. 5] (обычно этим местом считается Шри Парвата в Андхра Прадеше). Особого внимания заслуживает практически всеобщее убеждение местных историков, что Уддияна $(\rightarrow$ Оддияна $\rightarrow$ Одивища $\rightarrow$ Орисса) - мистическая страна дакинь буддийского тантризма, обычно локализуемая на горной границе Пакистана и Афганистана, - как раз и является современной Одишей.

Районы штата, в которых сейчас обитают 62 племени адиваси (аборигенов), и в наши дни сохраняют атмосферу дикой древности. Племенные верования были той почвой, на которой вырастали общеиндийские культы плотоядных богинь. Женский принцип шакти признан во всех индийских религиях и символизирует мощь энергии созидания. Деви (Богиня), по древней Маркандея-пуране, считается всеохватывающей, всеведущей, всемогущей как создательница, поддерживательница и разрушительница вселенной, и она рождена как совокупная энергия всех богов, поручивших ей уничтожение демонов. В тантрическом контексте разнообразные формы шакти становились личными божествами практикующих, а различие между индуистом и буддистом заключалось в реальности или символичности жертвоприношений, в мотивации (эгоизм или альтруизм) и цели (личная мощь и благо или польза других). В Ориссе проявлениям шакти молятся в образах Махисамардхини, Симхавахини, Парвати, Мангале, Кали, Вимале, Варахи, Чамунде, Гаури, Ардханаришвари, а также группам Дасамахавидий, Саптаматрик (всего в Ориссе известно 21 древнее изображение этих Семи матерей), 64 йогинь. Исторически первое найденное изображение (двурукая Вираджа из Джаджпура) относится к V в. н. э. Наиболее ярким примером включения в систему индуизма является распространённый образ Стхамбешвари (Кхамбешвари): племенной богини в форме колонны или шеста [3, p. 28-38]. Круглый, со стоками для крови храм 64 йогинь известен в Ранипуре Джхариале (Ranipur Jharial). Tам же находится Индралатх, кирпичный храм высотой 25 , в котором найдено немало и буддийских мотивов [12, p. 119].

Историки и археологи Одишы приводят множество свидетельств смешения и постепенного адаптирования буддийских образов и символов. Так, популярное божество Лакулиша, изображаемое с дубинкой в руках, вместе с тем обладает признаками будды - удлинёнными ушами, ушнишей (выступом на темени); руками, сложенными в мудре учения, и другими, в т. ч. - йогической повязкой на ногах. Он считается 28-м воплощением Шивы, а также основателем или систематизатором школы Пашупата (VII в.) [22, p. 175], вероятно, имевшим буддийские корни [12, p. 119].

Как уже упоминалось, местные исследователи (М. H. Shastri, B. Bhattacharya, H. C. Das) [15, p. 34-35] твёрдо убеждены, что Уддияна, страна дакинь, расположена в Калинге, что также упоминается в Калика-пуране. Махасиддха Сараха, живший во времена царя Субхакардевы I (правление ок. 780-800 гг.) династии Бхаумакара, и его ученик Луипа - родом из Одишы, так же, как и «великий совершенный» Каньхапа, чьим главным йидамом была Курукулла, и известный комментатор на Хеваджра-тантру Анангавиджра, не говоря уже о царе Индрабхути и его сестре Лакшминкаре (все VIII в.). Последняя известна как учитель сахаджайоги, учения о спонтанном, вне формальных практик, самоосвобождении [3, p. 10-11].

Великий мастер тантр, знаменитый учёный Наланды и Викрамашилы Абхаякарагупта (вторая половина ХІ в. - 1125 г.) был уроженцем Одишы [8, p. 22-32]. Наропа также некоторое время провёл в монастыре Ратнагири в районе Куттак. Даже в XVI в. буддизм существовал в Одише, как следу- 
ет из описаний Ачьютананды Даса, упомянувшего 4 школы философии и тантрические ветви, связанные с психоделическими практиками и алхимической традицией Нагарджуны, самым видным представителем которой был Вирасимха [19, p. 170, 176-177; 3, p. 11].

$$
\text { *** }
$$

Следующий раздел посвящён обозрению локальных памятников, на примере которых прослеживается типичная картина смены буддийского характера святилищ на индуистский.

Бхубанешвар, столица штата, переполнен старинными храмами, главный из которых - Лингарадж. Борьба между буддизмом и шиваизмом описана в Экамра-пуране как сражение богов и демонов, где последние подразумевают буддистов, терпящих поражение. Наибольшее усиление шиваитов связано с включением Калинги в империю бенгальца Шашанки (ок. 590-625 гг.), известного своим стремлением уничтожить дерево Бодхи. По-видимому, именно он выстроил шиваистский храм на месте буддийской ступы в местности Экамра, называвшийся Самовозникший Трибхубанешвар, откуда и пошло название города Бхубанешвар. Спустя несколько веков на месте храма Шашанки построили великолепный Лингарадж [3, p. 21-22].

Чрезвычайно интересен местный музей, в котором хранятся многочисленные памятники истории Одишы, в частности, капитель колонны Ашоки. Сами колонны были разобраны на лингамыл для шиваистских храмов; например, в храме Бхаскарешвар, на котором даже сохранились надписи письмом брахми $[11$, p. 83]. Другие находки с буддийскими мотивами поблизости от храма благодаря их стилистическим особенностям позволяют с уверенностью утверждать, что на этом месте около І в. до н. э. стояла не только колонна, но и ступа с оградой, украшенной рельефами $[15$, p. $50-54]$.

Город Пури на берегу Бенгальского залива - дом знаменитой троицы: Джаганнатха, его брата Балабхадры и их сестры Субхадры, где за священными статуями ухаживают около 6000 брахмановслужителей. В IX в. эти три глазастых божества были племенными божками, но постепенно они превратились в символы всемогущества, созидания и разрушения (Джаганнатх), воплощения грозного Бхайравы (Балабхадра) и Нарасимхи-Вишну (Субхадра). Точнее, Джаганнатх является аспектом Кришны, Балабхадра - формой Экапады, одноногого Бхайравы, т. е. формы Шивы, а истоки культа Субхадры также прослеживаются от Богини Колонны (Кхамбешвари, V-VI вв. н. э.), которой изначально поклонялись в верхней части долины Маханади [13, p. 51]. По легендам, Джаганнатху вначале молились как Синему Камню в пещере Нилакандара. Ему подносили цветы, плоды и молодых животных, и он воспевался как символ творения [16, p. 75]. То, что и в наши дни поклонники в знак почтения обходят божеств по-буддийски, правым плечом к центру, также указывает на буддийское происхождение комплекса. Кроме того, у этой триады устойчивые исторические ассоциации с тремя Драгоценностями: Буддой, Дхармой и Сангхой. За главным святилищем, вход в которое запрещён для не-индуистов, огороженная со всех сторон стеной, имеется статуя Будды [6, p. 43-52].

В наши дни Пури - это одна из главных религиозных столиц Индии, привлекающая в жаркие летние месяцы сотни тысяч паломников. В торжественной процессии триада божеств вывозится на огромной колеснице, под колёса которой некогда бросались благочестивые паломники с целью закончить свою никчёмную жизнь под взглядом высшего божества. Не исключено, что старинный город Дантапура, получивший своё название от ступы с зубом Будды, хранившимся там до того, как его увезли на Шри Ланку, как раз и является современным Пури [21, p. 404-405], ведь Джаганнатх это также титул Будды.

Этот великолепный храм XII в. был построен царём Чходагангой под влиянием проповедей великого вишнуита Рамануджи (1077-1157), и его наследники продолжали усердно покровительствовать распространению вишнуизма в Одише. Великая сила искусства способствовала дальнейшему распространению вишнуизма в творении Джаядевы «Гитаговинда», где синтез поэтической драмы и театрального искусства был настолько гармоничен, что завоевал своему создателю не только признание как поэта, но и вознёс его в ранг религиозного лидера. Шри Чантанья (1468-1533) принёс в Одишу нео-вайшнавизм в 1509 г., и с тех пор это течение здесь - доминирующее [3, p. 41, 50].

Из других буддийских памятников в дистрикте Пури следует отметить холм Арагарх (близ станции Деланга с деревней Харипур около селения Кхурда, также с курганом Барунай, дистрикт Пури). Курганы, скрывающие развалины монастырей и ступ, и обнаруженные на полях статуи и перекладины каменных ограждений позволили учёным отнести существование этого комплекса к IV в. н. э. и предположить, что монастырь назывался Бхора Сайла, а его самым известным обитателем был Дигнага, знаменитый буддийский логик. Поблизости также расположены памятники в деревне Бенупада (5 км от станции Деланга) и курган Тапанга около Нарангарха [15, p. 54-55]. 
Район побережья в сторону Ганджама и Андхры также был областью, где процветали буддийские учения и сохранилось много археологических памятников - в Джаугаде, Махендрагири, Санкараме, Куруме в районах Ramatirthan и Salihundam [14, p. 32].

Конарк с его храмом Солнца в 30 км к востоку от Пури, построенном в 1230-40 гг. [15, p. 10], знаменит своими эротическими скульптурами, отражавшими, как и Каджурахо, тантрические мотивы; сегодня он является популярным центром туризма.

Важнейший буддийский памятник на востоке Одишы - комплекс в Лалитгири, дистрикт Каттак (90 км от Бхубанешвара), где при раскопках 1985-1986 гг. были найдены шкатулки (каменные, серебряная, золотая) с реликвиями Будды $[17 ; 15$, р. 20]. Самые ранние находки здесь относятся к III в. до н. э., а разрушение комплекса связано с мусульманскими нашествиями XV в. Кирпичные фундаменты поздних (IX-XI вв.) четырёх монастырей были богаты находками изображений будд пяти семейств: Тары, Бодхисаттв, Дзамбхалы, - хранящихся в местном музее и указывающих на распространённость учений ваджраяны в то время. Комплекс венчает высеченная из камня ступа диаметром $15 м$ на холме.

В соседнем дистрикте Джаджпур расположены другие крупные буддийские археологические комплексы. В Удаягири (8 км от Лалитгири, VII-XII вв.) в монастыре Мадхавапура были также найдены многочисленные статуи бодхисаттв и будд, с особым акцентом на аспекты ваджраяны, наряду с множеством оснований ступ, больших и маленьких. Особенностью этого поселения был храм, посвящённый защитнику Махакале.

Первоначальное строительство Ратнагири (5 км от Удаягири) относится к V в. н. э. В этом комплексе из 3 монастырей, 8 храмов и большой, в окружении множества малых, ступы было выявлено множество статуй искусной работы, а из сочинений тибетских авторов известно, что специализацией местных учёных в начале II тыс. была Калачакра-тантра. С конца XIII в. монастырь постепенно пришёл в запустение [15, p. 70-80].

На соседнем холме Лангуди также обнаружены богатые буддийские находки, датируемые от III в. до н. э. до XV в. В ступе обнаружены надписи, напрямую сообщающие о её строительстве по приказу Ашоки, и раскопано большое многоэтажное здание, построенное по образцу монастырей в университетских комплексах центральной Индии. Судя по сохранившимся надписям, это, возможно, университет Пушпагири, описанный Сюань Цзаном и связанный с учениями махаяны [14; 15, p. 2930, 83-89; 5, II, p. 205]. Другая особенность этого места - множество изваянных на скале рельефов.

Но эти выдающиеся открытия представляют собой лишь вершину айсберга. Джаджпур - столица уже упомянутой династии Бхаумакара (736-910), многие правители которой были убеждёнными буддистами. Благодаря их поддержке в округе основаны десятки монастырей и храмов, преимущественно связанных с махаяной и ваджраяной, впоследствии разрушенных индуистами и мусульманами; и лишь отсутствие финансирования и надлежащего научного подхода препятствуют систематическим раскопкам многочисленных мест, упоминаемых в исследованиях краеведов. Все они обладают схожими чертами: наличием одного или нескольких монастырей, центральной и вотивными ступами, храмами, разнообразными, зачастую тантрическими скульптурами будд, бодхисаттв и местных божеств, трансформировавшихся в защитников буддийского учения. Здесь были обнаружены изображения Шакьямуни и других будд — глав семейств, а также бодхисаттв и йидамов Авалокитешвары, Майтрейи, Ваджрапани, Манджушри, Тары, Ваджраварахи, Ваджрабхайравы, Маричи, Чамунды, Махисамардини, Апараджиты, Херуки, Хаягривы [10] ${ }^{1}$.

\footnotetext{
${ }^{1}$ Другие перечисленные [15, p. 55-67] буддийские места, требующие дальнейшего исследования, следующие: Kakudia (по дороге между Jatni-Pipili); Achyutarajpur (1 км к западу от Банарпура, дистрикт Khurda); Tarapur (шоссе Cuttak - Paradeep, дистрикт Cuttak); Banesvarnasi и Kolangiri (берег Маханади близ Narasimhapur, дистрикт Cuttak, близ Ратнагири); Tarangasagarpur (Boudh Diha, 15 км к северо-востоку от Джаджпура); Alada (Lanka Dhia, дистрикт Jajpur) и Kopala; Solampur и Khadipada (Dhamnagar, дистрикт Bhadrak, с буддийскими образами в местных храмах Dwarabasini и Raghunath); в радиусе 10 км от Джаджпура, помимо упомянутых, следует отметить Vajragiri, Kolangiri, Ragadigiri, Ramesvara, Arada и Kapila; Jayarampur (Bhogarai, дистрикт Ваleswar); Ayodhya (25 км к западу от райцентра дистрикта Balasore, с множеством находок в полях); Khiching (25 км от Karanjia, дистрикт Mayurbhanja). В райцентре Баудх выше по течению Маханади была найдена большая статуя Будды и многие другие памятники, также в пригородах Shyamasundarpur и Pragalpur, а буддийские практики исторически продолжались в этом районе дольше всего. Далее, С. К. Патниак описывает Ganiapalli (8 км от Melchamunda, дистрикт Bargarh, V в., монастырь с необычной статуей Будды на сиденье из змей), Brahmаvana
} 
Современный буддизм в Одише в основном поддерживается тибетскими экспатриатами: так, в деревне Чандрагири южного дистрикта Гаджапати в 1963 г. был основан монастырь Пхюнцхог-линг (Ньингма - Дуджом) выходцев их Кхама и Пемако под руководством Намкхая Дриме Рабджама Ринпоче. В середине 1980-х гг. здесь же был возведён монастырь Тхубтен Миндрол-линг [18].

В заключение отметим, что происходившие в Одише процессы взаимодействия и интеграции индуизма и буддизма следовали общим паттернам, свойственным большинству регионов Индии, с поправкой на относительную изолированность древней и средневековой Калинги, которая обусловила снижение темпов брахманизации общества. Исторический процесс ассимиляции буддийских идей и практик на индийском субконтиненте заслуживает пристального внимания на материале, в обилии предоставляемом данными, имеющимися в публикациях историков школы Одиши, особенно в контексте ведущейся дискуссии о приоритетах и ценностях межрелигиозного взаимодействия [1].

\section{СПИСОК ИСТОЧНИКОВ И ЛИТЕРАТУРЫ}

1. Ерохин Б. Р. Буддизм ваджраяны и индуистский тантризм // Международный журнал исследований культуры. 2018. № 4. С. 69-90.

2. Blaine Walker. The Great River of Blessings. Rinchen Terdzo in Orissa India. Halifax, Highland Publications, 2011, $259 \mathrm{p}$.

3. Das H. C. "Religious Movements in Southern Orissa". Orissa Historical Research Journal, vol. XXXV, no. 3-4, 1989, pp. 1-56.

4. Davidson Ronald M. Indian Esoteric Buddhism. A Social History of the Tantric Movement. New York, Columbia University, 2002, $475 \mathrm{p}$.

5. Hiuen Tsiang. Su-Yu-Ki. Buddhist Records of the Western World. Tr. By Samuel Beal, vol. 1-2. London, Kegan Paul, 1906, 242+369 p.

6. Jamanadas K. Decline and Fall of Buddhism (A tragedy in Ancient India). New Delhi, Bluemoon Books Dalit EForum, 2001, $348 \mathrm{p}$.

7. The Jatakas, vol. I. Tr. by Robert Chalmers. Oxford, [n. a.], 1881, 324 p.

8. Lee Yong-Hyun. Synthesizing a Liturgical Heritage: Abhayakaragupta's Vajravali and the Kalacakramandala. PhD Dissertation, [n. a.], University of Wisconsin-Madison, 2003, 277 p.

9. Malalasekera G. P. Dictionary of Pāli Proper Names, vol. 1, 2. London - New Delhi, Munshiram Manoharlal Publishers Pvt Ltd, 1937, 1163+1370 p.

10. Mishra S. P. “Archaeological Remains at Jajpur”. Orissa Historical Research Journal, vol. XXXV, no. 1-2, 1990, pp. 39-46.

11. Misra P. K. Buddhism in Kalinga During Asoka. Orissa Historical Research Journal, vol. VII, no. 3-4, 1987, pp. 78-85.

12. Panda $S$. S. "New Light on the Brick Temples of the Upper Mahanadi Valley of Orissa”. Orissa Historical Research Journal, vol. XXXV, no. 3-4, 1989, pp. 117-126.

13. Panda S. S. "Antiquities of Shri Jagannath: Amazing Finder”. Orissa Historical Research Journal, vol. XLXII, no. 4, 2004, pp. 50-57.

14. Patnaik Debi. Ashoka stupa found in Orissa. 2000. URL: www.rediff.com/news/2000/may/27ashok.htm

15. Patniak S. K. Buddhist Heritage of Orissa. Bhubaneshvar, Mayur Publications, 2000, 200 p.

16. Patra H. "Sri Jagannath, Symbol of Creation". Orissa Historical Research Journal, vol. XXXV, no. 1-2, 1990, pp. 73-80.

17. Prusty H. C. "A Unique Buddhist site in Cuttack District, Orissa.” Orissa Historical Research Journal, vol. XXXVIII, no. 1-4, 1993, pp. 154-169.

18. Ripa. The Monastery in Orissa. URL: http://ripa-international.com/about/monasteries/orissa/

19. Sahu N. K. Buddhism in Orissa. Bhubaneshvar, Utkal University, 1958, 295 p.

20. Sahu N. K. Hinayana Buddhism in Eastern India in the 7th century A. D. Orissa Historical Research Journal, vol. IV, no. 1-2, 1990, pp. 39-46.

21. Tarthang Tulku (ed.). Holy Places of the Buddha. Crystal Mirror Series, vol. IX. Berkeley, Dharma Publ., 1994, 483 p.

22. Weiner Sheila L. From Gupta to Pala Sculpture. Artibus Asiae, 1962, 25 (2/3), pp. 167-192.

23. Yun-hua H. J. "On Chinese Translation of Avatamsaka - Sutra Original From Udra". Orissa Historical Research Journal, vol. VII, no. 3-4, pp. 1-11.

Поступила в редакцию 04.04.2019

(дистрикт Cuttak), Kuruma (8 км от Конарка, дистрикт Puri) [15, p. 80-82]. Ещё одно древнее буддийское место - Кесари-беда в 55 км от Пападаханди в дистрикте Корапут. Здесь находилась ступа Какха, в которой хранились принесённые Тапуссой и Бхалликой волосы и ногти Будды [3, p. 9]. 
Ерохин Борис Романович, кандидат исторических наук, соискатель ФГБУН «Институт востоковедения Российской академии наук» 107031, Россия, г. Москва, ул. Рождественка, 12

E-mail: ou.omnilux@gmail.com

\section{B.R. Erokhin \\ BUDDHIST HERITAGE OF KALINGA (ODISHA STATE, INDIA)}

DOI: $10.35634 / 2412-9534-2020-30-1-119-125$

The interaction between autochthonous, Buddhist and Hindu traditions here is regarded through the historical perspective basing on the material presented in publications of the state's historical school which describe the archaeological and epigraphic monuments of Odisha. Unlike the "brahminical" approach, which generally dominates the Indian historiography and diminishes the influence of Buddhism on the Indian subcontinent, the studies of the local school provide more attention to this factor forming the regional history. The introduction describes the early period of Kalinga's relationship with Buddhism. The main part of the article is dedicated to the evidence of the overwhelming presence of Buddhist tantric tradition and subsequent gradual adaptation of Buddhist images and symbols in Hinduism. Due attention is paid to the outstanding figures of Buddhism whose lives were connected with Odisha, and to the main archaeological sites of the state. The conclusion generalizes the historical process of assimilation of Buddhist ideas and practices on the Indian subcontinent, which ended in the 13-14 centuries by extinguishing Buddhism over the most part of the subcontinent.

Keywords: vajrayana, tantrism, hinduism, religious interaction, national historiography.

\section{REFERENCES}

1. Erokhin B. R. Buddizm vadzhrayany i induistskiy tantrizm [Vajrayana Buddhism and Hindu Tantrism]. Mezhdunarodnyy zhurnal issledovaniy kul'tury [International Journal of Cultural Studies], 2018, no. 4, pp. 69-90. (In Russian).

2. Blaine Walker. The Great River of Blessings. Rinchen Terdzo in Orissa India. Halifax, Highland Publications, 2011, $259 \mathrm{p}$.

3. Das H. C. "Religious Movements in Southern Orissa". Orissa Historical Research Journal, vol. XXXV, no. 3-4, 1989, pp. 1-56.

4. Davidson Ronald M. Indian Esoteric Buddhism. A Social History of the Tantric Movement. New York, Columbia University, 2002, $475 \mathrm{p}$.

5. Hiuen Tsiang. Su-Yu-Ki. Buddhist Records of the Western World. Tr. By Samuel Beal, vol. 1-2. London, Kegan Paul, 1906, 242+369 p.

6. Jamanadas $K$. Decline and Fall of Buddhism (A tragedy in Ancient India). New Delhi, Bluemoon Books Dalit EForum, 2001, $348 \mathrm{p}$

7. The Jatakas, vol. I. Tr. by Robert Chalmers. Oxford, [n. a.], 1881, 324 p.

8. Lee Yong-Hyun. Synthesizing a Liturgical Heritage: Abhayakaragupta's Vajravali and the Kalacakramandala. PhD Dissertation, [n. a.], University of Wisconsin-Madison, 2003, 277 p.

9. Malalasekera G. P. Dictionary of Pāli Proper Names, vol. 1, 2. London - New Delhi, Munshiram Manoharlal Publishers Pvt Ltd, 1937, 1163+1370 p.

10. Mishra S. P. “Archaeological Remains at Jajpur”. Orissa Historical Research Journal, vol. XXXV, no. 1-2, 1990, pp. 39-46.

11. Misra P. K. Buddhism in Kalinga During Asoka. Orissa Historical Research Journal, vol. VII, no. 3-4, 1987, pp. $78-85$.

12. Panda $S$. S. "New Light on the Brick Temples of the Upper Mahanadi Valley of Orissa". Orissa Historical Research Journal, vol. XXXV, no. 3-4, 1989, pp. 117-126.

13. Panda S. S. “Antiquities of Shri Jagannath: Amazing Finder”. Orissa Historical Research Journal, vol. XLXII, no. 4, 2004, pp. 50-57.

14. Patnaik Debi. Ashoka stupa found in Orissa. 2000. URL: www.rediff.com/news/2000/may/27ashok.htm

15. Patniak S. K. Buddhist Heritage of Orissa. Bhubaneshvar, Mayur Publications, 2000, 200 p.

16. Patra H. "Sri Jagannath, Symbol of Creation". Orissa Historical Research Journal, vol. XXXV, no. 1-2, 1990, pp. 73-80.

17. Prusty H. C. "A Unique Buddhist site in Cuttack District, Orissa.” Orissa Historical Research Journal, vol. XXXVIII, no. 1-4, 1993, pp. 154-169.

18. Ripa. The Monastery in Orissa. URL: http://ripa-international.com/about/monasteries/orissa/

19. Sahu N. K. Buddhism in Orissa. Bhubaneshvar, Utkal University, 1958, 295 p. 
20. Sahu N. K. Hinayana Buddhism in Eastern India in the 7th century A. D. Orissa Historical Research Journal, vol. IV, no. 1-2, 1990, pp. 39-46.

21. Tarthang Tulku (ed.). Holy Places of the Buddha. Crystal Mirror Series, vol. IX. Berkeley, Dharma Publ., 1994,483 p.

22. Weiner Sheila L. From Gupta to Pala Sculpture. Artibus Asiae, 1962, 25 (2/3), pp. 167-192.

23. Yun-hua H. J. "On Chinese Translation of Avatamsaka - Sutra Original From Udra". Orissa Historical Research Journal, vol. VII, no. 3-4, pp. 1-11.

Erokhin B. R., Candidate of History, Post-Graduate Researcher Institute of Oriental Studies of the Russian Academy of Sciences Rozhdestvenka st., 12, Moscow, Russia, 107031

E-mail: ou.omnilux@gmail.com 